\title{
Scaling down, scaling up: Development of a framework to understand vulnerability and change potential in the Hauraki, New Zealand
}

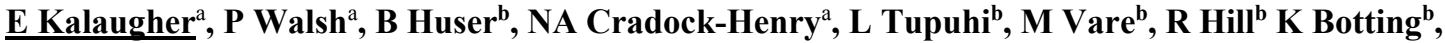 \\ K Andrews' ${ }^{c}$, G Greenhalgh ${ }^{\mathrm{a}}$ \\ ${ }^{a}$ Landcare Research \\ ${ }^{b}$ Waikato Regional Council \\ ${ }^{c}$ University of Waikato
}

Email: kalaughere@landcareresearch.co.nz

\begin{abstract}
In New Zealand, regional councils are responsible for developing and implementing policy, and realising objectives for natural resource management. Across the country, councils face the challenge of creating policies that will ensure the maintenance of ecosystem services, while future-proofing the social, cultural and economic viability of their regions in the face of multiple uncertainties and drivers of change.
\end{abstract}

The Hauraki subregion presents a "perfect storm" of interacting environmental, social and economic challenges. While wetland drainage at the turn of the $20^{\text {th }}$ century transformed the landscape, and provided superior land for dairy farming land and associated livelihoods, this low lying coastal area now faces multiple socio-economic and environmental challenges. The legacy effects - drainage, peat shrinkage and land subsidence, salt water intrusion, and biodiversity loss - are exacerbated by changing land use and land management practices. Climate change and the risk of increasing variability and extremes, as well as social and economic drivers, further complicate the scope for policy-, planning- and adaptation solutions. In addition, there are a wide range of stakeholders in a highly complex social and political environment, including settlement claims by Māori, the indigenous people of New Zealand, under the Treaty of Waitangi; a Marine Spatial Plan developed with stakeholders from around the wider Hauraki Gulf; and an upcoming review of the Regional Plan and Regional Coastal Plan.

The Hauraki is diverse and spatially heterogenous, implying that impacts from different driving forces will be felt in different ways by different communities. In the past, integrated assessments for the purpose of policy development have tended to focus on region- or sub-regional scale modelling of high level scenarios. Such assessments can be a useful tool to understand broad scale issues, but from the outset they often limit the scope for understanding local-level vulnerabilities and innovation potential.

In order to develop effective policies, we suggest that vulnerability and innovation potential need to be both considered spatially and understood at different scales. To this end, we propose a framework, developed by Landcare Research together with the Waikato Regional Council (WRC), for an integrated assessment process intended to address the challenges described above and to underpin policy development. We approach the assessment both at the broader scale, through spatial mapping and the development of indices of environmental as well as socio-economic and cultural vulnerability; and at the local scale through the spatial identification of hotspots of vulnerability and local capacity for change, where we are able to explore placebased, adaptive pathways. Based on the premise that change can occur most efficiently, equitably and effectively where the need for such change is recognised across different parts of the community, and where there is a shared vision and direction, we propose that the understanding of vulnerability and innovation potential generated from the development of local-scale, place-based visions that cut across sectors can then be scaled up to help inform broader policy questions and future scenarios.

Keywords: Scale, integrated assessment, pathways, policy development, vulnerability, adaptation 
Kalaugher et al., Scaling down, scaling up: Understanding vulnerability and change potential in the Hauraki, New Zealand

\section{INTRODUCTION}

In New Zealand, regional councils are responsible for developing and implementing policy and realising objectives for natural resource management. Across the country, councils face complex challenges to develop policies that will support environmental outcomes, while future-proofing the social, cultural and economic viability of their regions in the face of multiple uncertainties and diverse drivers of change. As a basis for policy development, integrated assessments are increasingly drawn on as an approach to understand the main interactions at play in a particular region or subregion and to assess the likely costs and benefits of potential solutions to environmental problems.

In the past, such assessments have tended to focus on regional- or subregional scale modelling of high level scenarios. This can provide a useful mechanism to understand the cumulative effects of broad scale issues and to quantify some broadly applicable solutions. However, they face key limitations:

1. Integrated, high level models are often extremely complex. Their internal logic may be inaccessible to the wider public, limiting the potential for evidence-based public engagement on interactions and potential solutions.

2. While social and cultural elements of such assessments are generally acknowledged as important, they are often difficult to quantify and as a result, poorly integrated with environmental and other factors.

3. Because of the high level and quantitative nature of such assessments, they can limit the scope for understanding both vulnerabilities and innovation potential at the local level.

4. Collaborative processes tend to be conducted with sectoral representatives tasked with defending sectoral interests, limiting discussion around place-based solutions.

There is an increasing body of literature on principles for a more integrated and interdisciplinary natural resource management (e.g. integrated landscape management (Sayer et al 2013), ecosystem approach (Diaz et al. 2015, Millennium Ecosystem Assessment 2003)) as well as frameworks such as the sustainable livelihoods (Haidar, 2009) and climate change adaptation frameworks (see Dessai et al. 2005) that have been applied primarily in developing countries. In the face of increasing pressure on both economic and environmental goals, there is a need for stepwise approaches that can support local government in developed countries such as New Zealand to develop a shared vision of the future and enable innovation at different scales. In the climate change context, it has been suggested that the appraisal of adaptation options should be given greater attention (Wilby and Dessai 2010).

The Hauraki subregion is defined by two main river catchments the Waihou and Piako and presents a "perfect storm" of interacting environmental, social and economic challenges. While wetland drainage at the turn of the $20^{\text {th }}$ century transformed the landscape, and provided superior land for dairy farming land and associated livelihoods, this low lying area now faces multiple socio-economic and environmental challenges. The legacy effects of drainage, peat shrinkage and land subsidence, salt water intrusion, and biodiversity loss - are exacerbated by intensified land use and land management practices. Climate change and the risk of increasing variability and extremes, as well as social and economic drivers further complicates the scope for policy, planning and adaptation solutions. In addition, there are a wide range of stakeholders in a highly complex social and political environment, including settlement claims under the Treaty of Waitangi, a Marine Spatial Plan developed with stakeholders from around the wider Hauraki Gulf, and an upcoming review of the regional planning documents. The area is socially diverse and spatially heterogeneous, implying that impacts from different driving forces will be felt in different ways by different communities.

In this paper, we propose a framework, developed by Landcare Research together with the Waikato Regional Council (WRC), for an integrated assessment process intended to address the challenges described above and to underpin the development of policy that will enable innovative approaches to the challenges faced by residents of the Hauraki subregion.

\section{APPROACH}

To develop the framework for integrated assessment we draw on a number of conceptual approaches from the literature including vulnerability, ecosystem services, and adaptation pathways. First, we consider the components of vulnerability as explored in the climate change literature (e.g. Adger 2006). Vulnerability is considered to be a function of exposure, sensitivity and adaptive capacity. For the purposes of an integrated assessment, it is necessary to consider these components not only in relation to climate change but to a range of different drivers of change that the subregion will be exposed to.

In order to consider sensitivity of the subregion to these drivers, we first need to identify what it is that we wish to maintain or enhance. Most regional councils have considered this subject in depth, and any integrated 
Kalaugher et al., Scaling down, scaling up: Understanding vulnerability and change potential in the Hauraki, New Zealand

assessment must be embedded in this work in order to be effective. In WRC's Strategic Direction 2016 2019, the council has identified three overarching objectives: A healthy environment; strong economy; and vibrant communities. This work aims to support WRC's strategic and policy direction as expressed in: the Strategic Direction, where both long term outcomes and priorities for 2016 - 2019 are set, and implementation of the Waikato Regional Policy Statement (RPS), including through the Resource Management Act (1991) regional plan change process (review of the Regional Plan and Regional Coastal Plan). It is in line with the Regional Policy Statement (RPS) Objective 3.8 ("recognizing, maintaining and enhancing a wide range of ecosystem services"), in that the assessment is informed by an ecosystem services and natural capital approach. In New Zealand, co-governance of natural resources with Māori is also an important component of any policy process. Māori perspectives and concerns are integrated throughout the framework, but also considered independently in the context of cultural sensitivity (Figure 1).

To develop effective policies, we suggest that vulnerability and innovation potential need to be both considered spatially and understood at different scales. There is an ongoing tension in any planning process between the need to find broad scale solutions and understand the way different issues interact at regional and subregional level; and the in-depth understanding of potential for change and collaboration that is only possible at a smaller, local scale. In scenario planning at the broader scale, for example, it is possible to summarise potential outcomes for specific actions. However, such assessments are limited to the both the data that is already available, and the interactions that can be adequately quantified. This presents a bottleneck to the development of potential solutions and hence limits innovation.

Looking for solutions and future pathways at a local scale presents a number of advantages. In particular, collaboration at this scale is often driven by a shared sense of place, providing common ground. Solutions have the potential to be more spatially explicit and flexible, and negotiations require less broad scale data as the environment in question is directly familiar to those negotiating. Greater familiarity of those involved may also lend itself to more innovative solutions. Based on the premise that change can occur most efficiently, equitably and effectively where the need is recognised across different parts of the community, we propose that the most vulnerable areas represent the most fertile ground to explore adaptive pathways and locate resources to potentially support innovative, transformational change in that area.

We therefore propose a six-step process framework that weaves between the two scales to understand both local level adaptation potential and potential policy levers and catalysts for change. This six-step process is not intended to be carried out in isolation, but rather provides a framework to support councils in bringing together existing programmes and processes. The framework is also intended to support engagement, as a means of catalysing conversation about the future of an area at different scales (Figure 1):

1. First, we inventorise the capital or resources available in the system: This includes both the capital underpinning key ecosystem services; and resources that may provide opportunities and contribute to adaptive capacity.

2. In order to assess exposure, we identify the main drivers of change for the subregion. Sensitivity of ecosystems to drivers of change will depend not only on each individual driver but how these interact to compound vulnerabilities.

3. Spatial assessment of environmental, socio-economic and cultural sensitivity: We draw on an ecosystem services framework to spatially assess the relative environmental sensitivity (to the key drivers of change) of the capital that underpins ecosystem services. The socio-economic sensitivity assessment draws on the vulnerability context, and specific consideration is given to Māori cultural vulnerability. The spatial identification of hotspots of vulnerability is intended both to identify the spatial variability in issues facing the subregion; and to identify locations in which to explore place-based, adaptive pathways. For this purpose, priority areas are identified where the combined effects of multiple social, economic and/or environmental stressors are most prevalent and current and potential benefits (ecosystem services) most compromised.

4. Resources for adaptation: In parallel to the sensitivity assessment, we seek to spatially identify key resources underpinning adaptive capacity in the area. This is focused on local groups and institutions with potential to provide network nodes and catalyse potential solutions, potentially underutilized capital/resources, or obligations to carry out environmental works that are written into resource consent conditions, for example mining consents. This spatial analysis is primarily intended to catalyse further conversation about adaptive pathways, at local level. 
Kalaugher et al., Scaling down, scaling up: Understanding vulnerability and change potential in the Hauraki, New Zealand

5. Adaptation Pathways approaches have been developed to compare possible futures under climate change to support regional policy planning and strategic decision-making processes under conditions of uncertainty. It provides a framework to consider multiple possible social, economic and climate futures; to test the robustness and flexibility of adaptation options and avoid path dependency. We will draw on this approach to run workshops in the identified hotspots for the development of local level adaptive pathways under multiple drivers of change.

6. The information and understanding gained from these workshops can then inform higher level policy questions and scenario development.

\section{RESULTS}

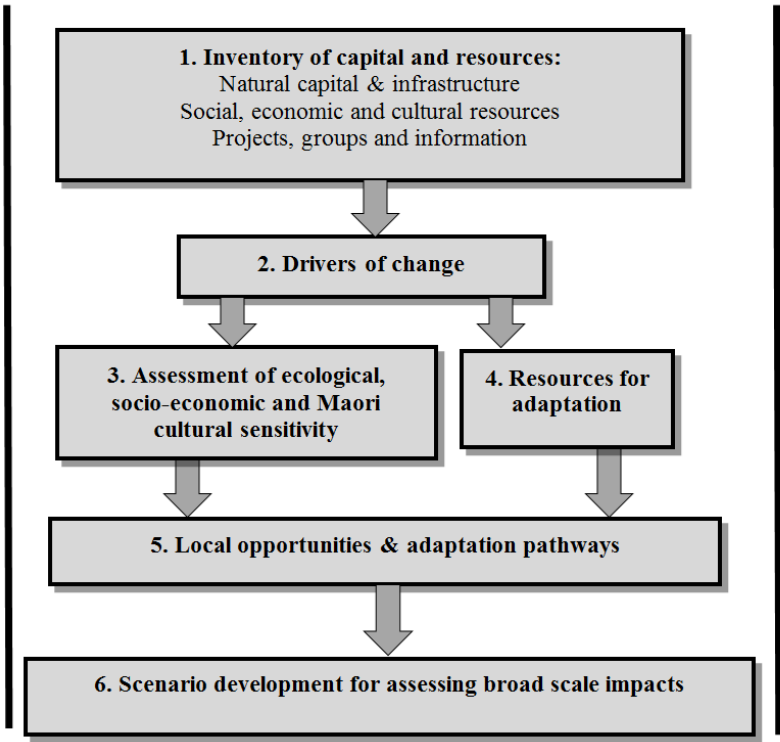

SUBREGIONAL LEVEL

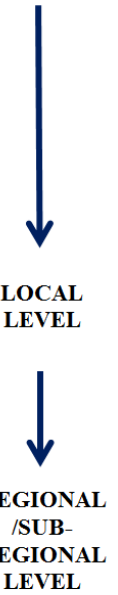

Figure 1. Proposed approach to an integrated assessment of the Hauraki

The development of this framework has been an ongoing, iterative project with Landcare Research and the WRC. It is anticipated that the framework will continue to develop and it is intended to be a flexible tool that can be adapted to suit the context of other regional councils in New Zealand. Work to date has been focused on co-development of the framework, and we anticipate completing step five in the coming months.

\subsection{Inventory}

The first step in this assessment was to conduct an inventory of sources of information about resources in the area and programmes of work, as well as key people and groups conducting activities. This was intended to help identify not only the activities in the subregion, but also the past emphasis on those activities. We identified and categorised 244 projects taking place in the subregion, by both district and theme.

We considered a number of approaches available for categorizing capital, such as the sustainable livelihoods approach in which five different kinds of capital are identified (Haidar, 2009). However, for the purpose of this assessment we took a simplified approach.to identifying sources of biophysical, social and economic data. The inventory identified biophysical data related to a wide range of environments and scales; and a significant amount of social data, much of which was also available for the rest of the Waikato Region or New Zealand. Most social data was reported at the territorial authority or census area unit scale, with some only available at regional level. Economic data available is also mostly based on census data.

\subsection{Drivers of change}

A driver of change is defined in chapter 7 of the Millennium Ecosystem Assessment (MEA) as "any natural or human-induced factor that directly or indirectly causes a change in an ecosystem" (Millennium Ecosystem Assessment, 2003). Drivers may directly influence ecosystem processes, or operate more indirectly, by causing changes to direct drivers. In the more recent IPBES conceptual framework, natural and anthropogenic drivers are considered separately (Diaz et al. 2015).

We drew on the drivers of change identified in the WRC's Strategic Direction as a starting point for this step, and compared this with the outputs of the inventory to identify important drivers of change for the Hauraki. A selection of those key indicators that can be mapped spatially was then identified and assessed in a workshop with key WRC staff. Table 1 presents a set of layers selected to provide insights into the direction and overall trend of some significant drivers.

The drivers of change are not intended to be comprehensive but rather a meant to represent the main issues facing the Hauraki in such a way that the interactions between the different components of vulnerability can be highlighted and analysed. For each layer, the trend of change was identified, where possible, for the last 10-20 years. This is done in a simple format, without modelling, in order to enable the simple inclusion of different layers on different time scales, and enable open discussion around the issues. 
Kalaugher et al., Scaling down, scaling up: Understanding vulnerability and change potential in the Hauraki, New Zealand

Table 1. Drivers of change identified for the Hauraki

\begin{tabular}{|c|c|c|}
\hline Strategic & Hauraki issues & Spatial layers selected \\
\hline Regional risks & $\begin{array}{l}\text { Climate change and variability } \\
\text { Sea level rise, salt water incursion } \\
\text { Flooding } \\
\text { Coastal erosion and mangroves } \\
\text { Biosecurity }\end{array}$ & $\begin{array}{l}\text { Potential evapotranspiration deficit (PED) } \\
\text { Flood hazards and (flood) protected areas. } \\
\text { Land cover database (mangroves) } \\
\text { Possum risk map } \\
\text { NZ Fundamental Soils Layer - salinity }\end{array}$ \\
\hline Declining natural capital & $\begin{array}{l}\text { Loss of biodiversity and natural vegetation } \\
\text { Nutrient loading in waterways. } \\
\text { Sediment loading of waterways } \\
\text { Contamination of groundwater and soils } \\
\text { Changes in the productive capacity of land }\end{array}$ & $\begin{array}{l}\text { Percent indigenous vegetation } \\
\text { WRPP models } \\
\text { Heavy metals in soil } \\
\text { Peat shrinkage (LCDB) }\end{array}$ \\
\hline Iwi Māori influence & $\begin{array}{l}\text { Increasing political and economic influence, treaty } \\
\text { settlements }\end{array}$ & Treaty of Waitangi settlements \\
\hline Economic trends & GDP per sector, per capita & Median household income \\
\hline Demographic changes & Population growth and ethnicity & $\begin{array}{l}\text { Change in population (total) } \\
\text { Change in ethnic groups }\end{array}$ \\
\hline Government influence & $\begin{array}{l}\text { Promotion of agricultural development } \\
\text { Responsibilities e.g. Ramsar sites. }\end{array}$ & Protected areas \\
\hline Technology change & Irrigation and drainage & $\begin{array}{l}\text { Drainage schemes and irrigation } \\
\text { Effluent discharge consents }\end{array}$ \\
\hline Development trends & $\begin{array}{l}\text { Changes in land ownership } \\
\text { Urbanisation, lifestyle blocks } \\
\text { Changes in land use, increased stocking rates }\end{array}$ & $\begin{array}{l}\text { Agribase } \\
\text { Roading and cycleways } \\
\text { Building consents }\end{array}$ \\
\hline $\begin{array}{l}\text { Changing values, } \\
\text { perceptions and ideas }\end{array}$ & Environmental attitudes & Surveys are available, but not spatially specific \\
\hline
\end{tabular}

\subsection{Sensitivity analysis}

For this step in the assessment, we consider separately the ecological, socio-economic and Māori cultural sensitivity of the area. We draw on an ecosystem services framework to spatially assess the relative sensitivity of capital identified that underpins ecosystem services. In order to more specifically address social and economic vulnerability, we have also developed an economic and social vulnerability assessment index. Further, we independently consider aspects of Māori cultural vulnerability. The selection of spatial layers took into account previous work done by WRC on ecosystem services (e.g. Hart et al 2013), as well as relevance to WRC's strategic direction.

This broad scale mapping can be used to identify hotspots of vulnerability, where particular drivers of change interact with areas of high sensitivity. These areas are facing multiple stressors and as a result, the community may be more willing to engage in the exploration of adaptive pathways. They may already be considering options for change or involved in processes at local level to address place-based problems.

\section{Ecological sensitivity}

Biophysical data were identified relating to a wide range of environments and varying in scale. In order to select layers that would represent the main ecological sensitivities in the Hauraki spatially, we categorized the data identified in the inventory according to an ecosystems services approach, building on preliminary work to identify and prioritise ecosystem services for the Waikato (Hart et al. 2013) and considering provisioning, regulating, cultural, and supporting services. In a workshop with key WRC staff, we then worked through each of these categories, identifying the relative importance of particular services in the Hauraki context, which aspects of natural capital are key to the provision of these services, and which elements can be mapped spatially. We also built on previous work conducted by WRC on ecosystem services and in the context of the Waikato Regional Prioritisation Project (Hill et al. 2015) which has created environmental indices to identify priority catchments and sub-catchments for WRC work programmes.

In several cases, there is overlap between the natural capital identified and the layers selected to represent drivers of change. In this case, however, the focus is on the current state. This process also highlighted gaps in the data we have available on the provision of particular ecosystem services, for example biological control, disease control, and of particular importance, pollination.

\section{Socio-economic sensitivity}

In order to specifically consider the socio-economic sensitivity of the communities dependent on the ecosystem services identified, we developed a separate socio-economic vulnerability index. This work leverages previous literature on social and economic vulnerability, including the Social Vulnerability Index (SoVI) (Cutter et al. 2003) and the New Zealand Deprivation Index (Salmond et al. 1998). 
Kalaugher et al., Scaling down, scaling up: Understanding vulnerability and change potential in the Hauraki, New Zealand

To develop the index, a large set of 42 economic and social variables was drawn from the New Zealand Census (2013) meshblock datasets (meshblocks are the smallest geographic unit for which statistical data is reported by Statistics NZ). These were selected to be in line with the SoVI and the NZ Deprivation Index, with the addition of several variables representing broader economic and social vulnerability. As the analysis is concerned with comparative vulnerability, the full set of national meshblocks is used to calibrate the analysis. Assessment of data quality and removal of variables with high collinearity (following Cutter et al. 2003) reduced the final set of variables to 35 . To facilitate comparability, all variables are transformed into percentage of total observations in the meshblock. This final set of variables is then used in a principal components analysis to develop the ESVI. A paper describing this process is in preparation.

\section{Mäori cultural sensitivity}

While issues relevant to Māori are considered throughout the assessment, this step provides space to consider independently the degree to which they can be considered spatially. Māori recognise a strong place-based spiritual and intergenerational connection to the land, the coastal environment and rivers, geothermal resources, historic places and all living species. Remaining traditional resources such as flax and wildfood species such as eels are particularly significant.

However, there is an ongoing tension between the need to collect data to help incorporate such considerations into broad scale assessments, and the caution from Māori in sharing culturally sensitive information that may be interpreted out of context. Context and connectedness to place have a particularly strong significance in Māori culture. For the purpose of the current assessment, Treaty of Waitangi settlement areas are included under the second step as a driver of change. In addition, the probable location of one eel species that has been identified as a key source of traditional wildfood is mapped spatially. The location of Marae, which are focal points for the Māori community, and the location of eel are mapped both as a potential sensitivity and a potential opportunity. More specific consideration of areas important to Māori should be given at local level.

\subsection{Resources for adaptation}

Identifying potential resources for adaptation is something that can be initiated spatially, but only as a broad indication, to catalyse discussion. For many resources that can be identified, the weight and potential of each resource may only become apparent at the local scale. For example, spatial mapping of community groups is not always an accurate representation of their level of activity, size of membership or the issues they address.

Potential resources identified include the location of marae and sports clubs, schools, farming and community groups; location of recreational and tourism facilities, and resource consents requiring environmental works as part of the consent conditions. Other opportunities include consideration of maps of potential biodiversity that have been created for part of the area, including restoration scenarios that can help to frame communitybased approaches to meet restoration goals. These 'resources' are not intended to be mapped as hotspots, but rather gathered as potential sources of adaptive potential and community connectedness, with a view to catalyzing positive conversations at local level.

\subsection{Local opportunities and adaptation pathways}

Adaptation pathways are an analytical approach to facilitate planning and strategic decision-making under conditions of uncertainty. A pathways approach considers multiple possible futures and tests the robustness and flexibility of adaptation options across these futures to avoid 'lock in', and inform decision making.

Of key importance will be a clear understanding of and flexible approach to effective co-ordination with other initiatives taking place in the areas identified, such as WRC's Local Indigenous Biodiversity (LIBs) programme, and the work of community groups.

\subsection{Scenario development}

Scenario planning and analysis will be an important tool to explore plausible futures (20-50 years) for the Hauraki, both to quantify as far as possible the impacts of potential options for policy development; and as a tool for public engagement. These qualitative, descriptive stories about the future will then be translated into quantitative assumptions providing input for modelling. A number of models are available for this work, for example the regional spatial Waikato Integrated Scenario Explorer (WISE) (Rutledge et al 2016); as well as other ongoing work, for example zonation-based ecological network modelling and farm level modelling.

The incorporation of local-level adaptive strategies into these scenarios will not be without challenges. However, we propose that the understanding of vulnerability and innovation potential generated from the development of local-scale, place-based visions will provide a firm anchor and cross-reference for the high level scenario development. It will enable a conversation at subregional level that connects to particular 
Kalaugher et al., Scaling down, scaling up: Understanding vulnerability and change potential in the Hauraki, New Zealand

people and places, enhancing the accessibility of the scenarios. In particular, it will provide a cross-check to ensure that the right questions are asked of the models, and that issues and resources that cannot be quantified are taken into consideration together with the modelled outputs.

\section{CONCLUSIONS AND NEXT STEPS}

The development to this framework to date has been a journey involving primarily a range of staff from Landcare Research and the Waikato Regional Council. In order to fully test its applicability and continue this iterative development process, involvement will be required from a broader range of stakeholders at different levels, including the local-level workshops in vulnerability hotspots.

The spatial mapping of drivers of change, ecosystem services, social and cultural sensitivity provides an important tool for engagement for the workshops, providing a temporal and spatial context in which to analyse and discuss the relative weight and merit of the issues identified for a particular area, potential adaptation opportunities, support required and finally, the kind of policy environment that would support such changes. However, the identification and collection of appropriate data is a time-intensive process.

The development of policies that will be broadly applicable, while supporting and stimulating innovation and positive change at a local level, is an ongoing challenge for many regions in New Zealand and around the world. The journey itself, and in particular the conversations catalyzed and understanding generated as a result of this process, are in this case as important as the final product.

\section{REFERENCES}

Adger, W.N. (2006). Vulnerability. Global Environmental Change 16 (3), 268-281.

Cutter, S. L., B. J. Boruff and W. L. Shirley (2003). Social Vulnerability to Environmental Hazards. Social Science Quarterly 84(2): 242-261.

Dessai, S., X. Lu, and J.S. Risbey (2005). On the role of climate scenarios for adaptation planning. Global Environmental Change. 15, 87-97.

Díaz, S., Demissew, S., Carabias, J., Joly, C., Lonsdale, M., Ash, N., ... Baldi, A. (2015). The IPBES Conceptual Framework - connecting nature and people. Current Opinion in Environmental Sustainability 2015 (14)1-16.

Haidar, M. (2009). Sustainable Livelihoods Approaches: The framework, lessons learnt from practice and policy recommendations. Economic and Social Council, United Nations.

Hart, G, D. Rutledge, M. Vare, and B. Huser (2013). An evaluation and prioritisation of ecosystem services models for inclusion into the Waikato Integrated Scenario Explorer (WISE). WRC TR 2013/28.

Hill, R., D. Borman, K. Neilson and J. Leathwick (2015). Waikato regional prioritisation project: preliminary results. WRC Internal Series 2015/08.

Leathwick, J. (2016). Integrated biodiversity ranking and prioritisation for the Waikato region. WRC TR 2016/12

Rutledge DT, Cameron M, Briggs C, Elliott S, Fenton T, Hurkens J, McDonald G, McBride G, Phyn D, Poot J, Price R, Schmidt J, van Delden H, Tait A, Urich, P Vanhout, Woods R (2016). WISE: Waikato Integrated Scenario Explorer. Technical specifications, Version 1.4. WRC TR 2016/16

Sayer, J, S. Sunderland, J. Ghazoul, J-L Pfund, D. Sheil, E. Meijaard, M.Venter, A. Klintuni Boedhihartono, M. Day, M, C. Garcia, C. van Oosten and L.E. Buck (2013). Ten principles for a landscape approach to reconciling agriculture, conservation, and other competing land uses. PNAS 2013110 (21)8349-8356.

Salmond, C., P. Crampton and F. Sutton (1998). NZDep91: A New Zealand index of deprivation. Australian and New Zealand Journal of Public Health 22(7): 835-837.

Millennium Ecosystem Assessment (2003). Ecosystems and Human Well-being: A Framework for Assessment

Waikato Regional Council (2016). Our strategic direction 2016-2019 Tā Tātou Rautaki Whakamua.

Wilby, R.L., Dessai, S. (2010). Robust adaptation to climate change. Weather 65 (7), 180-185. 